УДК 539.216

\title{
ОПТИЧЕСКИЕ И ЭЛЕКТРИЧЕСКИЕ СВОЙСТВА ПЛЕНОК ZnSe, ПОЛУЧЕННЫХ МЕТОДОМ ГИДРОХИМИЧЕСКОГО ОСАЖДЕНИЯ
}

\author{
(C) 2015 г. Е. М. Софронова*, В. В. Стариков**, Д. С. Софронов*, Е. И. Костенюкова**, \\ А. М. Лебединский $* * *$, П. В. Матейченко**** \\ * НТК “Институт монокристаллов” Национальной академии наук Украины, Харьков \\ ** Национальный технический университет "Харьковский политехнический институт” \\ *** Национальный исследовательский Томский политехнический университет \\ **** Институт монокристаллов Национальной академии наук Украины, Харьков \\ e-mail: sofronov@isc.kharkov.com \\ Поступила в редакцию 14.10.2014 г.
}

\begin{abstract}
Методом гидрохимического осаждения получены пленки селенида цинка при взаимодействии оксида цинка с селеном в присутствии гидразина и сульфита натрия в щелочной среде. При всех использованных условиях осаждения формируется сфалеритная модификация $\mathrm{ZnSe}$, для которой значения ширины запрещенной зоны находятся в пределах 2.6-2.7 эВ. С ростом концентрации сульфита натрия в растворе средний размер частиц увеличивается до 0.75 мкм (при соотношении $\mathrm{Zn}^{2+}$ : $\left.\mathrm{SO}_{3}^{2-}=1: 10\right)$.
\end{abstract}

DOI: $10.7868 / \mathrm{S} 0002337 \mathrm{X} 15080151$

\section{ВВЕДЕНИЕ}

Халькогениды двухвалентных металлов широко применяются в качестве детекторов УФ-, гамма- и рентгеновского излучений ( $\mathrm{ZnSe}, \mathrm{ZnSe}(\mathrm{Te})$, $\mathrm{CdTe})$, солнечных преобразователей энергии $(\mathrm{CdS} / \mathrm{CdTe})$, сенсоров (CdSe/ZnS), ИК-сенсоров и оптических элементов (HgTe, $\mathrm{ZnSe}, \mathrm{CdTe})$ [1-6]. Интерес к этому классу соединений объясняется сочетанием в них физических свойств, позволяющих использовать кристаллы на их основе в приборах оптики, акустики, электроники, ядерной физики и др. Для халькогенидов наблюдается высокая взаимная растворимость компонентов с образованием твердых растворов замещения, что позволяет на их основе синтезировать новые материалы с заданной шириной запрещенной зоны, требуемым диапазоном пропускания и другими необходимыми характеристиками. Наиболее востребованными являются материалы на основе $\mathrm{ZnSe}$, что объясняется их применением в многоэнергетических детекторах рентгеновских сканеров, компьютерных томографах и светодиодах [6, 7]. Пленки на основе $\mathrm{ZnSe}$ используют в качестве окон тандемных фотопреобразователей солнечной энергетики высокой эффективности [8].

Один из простых способов получения пленок $\mathrm{ZnSe}$ - метод гидрохимического осаждения, позволяющий получать пленки из водных растворов с использованием в качестве селенирующего реагента селеномочевину или селеносульфат натрия [9-11]. Также в качестве селенирующего реагента возможно использование элементарного селена
[12]. В этом случае процесс формирования пленок происходит в щелочных растворах (1-5 M). Показано, что независимо от концентрации щелочи образуется кубическая модификация селенида цинка (сфалерит), характеризующаяся шириной запрещенной зоны $E_{g}=2.6-2.8$ эВ. Пленки сформированы сферическими частицами с размером 0.15-1 мкм.

Известно, что на процесс формирования частиц значительное влияние оказывает анионный состав $[13,14]$, что позволяет управлять морфологическими характеристиками частиц. В качестве дополнительного компонента при формировании пленок $\mathrm{ZnSe}$ можно использовать сульфит натрия, который будет также оказывать селенирующее действие.

Таким образом, целью данной работы являлось изучение влияния сульфита натрия на процесс осаждения пленок $\mathrm{ZnSe}$ из $3 \mathrm{M}$ раствора $\mathrm{NaOH}$ и их оптических и электрических свойств.

\section{ЭКСПЕРИМЕНТАЛЬНАЯ ЧАСТЬ}

Материалы. Для синтеза использовали $\mathrm{ZnO}, \mathrm{Se}$, $\mathrm{NaOH}$ и гидрат гидразина квалификации “х. ч." фирмы "Реахим". Растворы готовили на дистиллированной воде.

Осаждение пленок. В качестве подложки использовали стекло, нержавеющую сталь марки $12 \mathrm{X} 18 \mathrm{H} 10 \mathrm{~T}$ и оцинкованное железо. Перед нанесением пленок поверхность подложек обезжиривали в 3 М растворе гидроксида натрия в тече- 
ние 30 мин при температуре $80-90^{\circ} \mathrm{C}$ с последующей неоднократной промывкой дистиллированной водой. Металлические подложки перед обезжириванием дополнительно травили в $10 \%$-ном растворе азотной кислоты в течение 20 мин при температуре $70-80^{\circ} \mathrm{C}$. Пленки на поверхности подложек получали по следующей методике [12]: в круглодонную колбу на 250 мл помещали подложку, приливали 100 мл 3 М раствора гидроксида натрия, после этого добавляли 0.081 г оксида цинка, 0.079 г селена, 0.1 мл гидрата гидразина и $0.5-10$ мл $1 \mathrm{M}$ раствора сульфита натрия. Реакционную смесь нагревали до $80-85^{\circ} \mathrm{C}$ и выдерживали при этой температуре в течение 1 ч. Полученную пленку промывали дистиллированной водой, затем этанолом и сушили при комнатной температуре в течение 2 ч.

Оборудование. Кристаллическую структуру осажденных пленок определяли методом рентгеновской дифрактометрии в геометрии БрэггаБрентано с графитовым монохроматором на первичном пучке в $\mathrm{Cu} K_{\alpha}$-излучении. Исследование морфологии полученных пленок проводили с использованием сканирующего электроного микроскопа (СЭМ) JSM-6390LV. Оптические характеристики полученных конденсатов измеряли с помощью спектрофотометра СФ-26 в интервале длин волн $\lambda=360-1200$ нм. Снимали спектральные зависимости коэффициента отражения $R(\lambda)$ и пропускания $T(\lambda)$. Для получения спектров $R(\lambda)$ использовалась приставка ПЗО-2, которая обеспечивала при съемке двойное отражение света от поверхности экспериментальных образцов. Толщину пленок контролировали с помощью микроинтерферометра Линника МИИ-4.

ИК-спектры получены в таблетках с $\mathrm{KBr}$ на Фурье-ИК-спектрофотометре SPECTRUM ONE (PerkinElmer).

Для изучения электрического сопротивления пленок снимались вольт-амперные зависимости. Расчеты сопротивления проводились для омического участка вольт-амперных характеристик (BAX). Измерительная схема для съемки ВАХ включала: источник стабилизированного напряжения ЛИПС 11А-30; вольтметр В7-38, измеряющий напряжение в диапазоне $10^{-6}-10^{3}$ В с входным сопротивлением до $10^{9}$ Ом; мультиметр Щ300 с чувствительностью по току $10^{-8} \mathrm{~A}$.

\section{РЕЗУЛЬТАТЫ И ОБСУЖДЕНИЕ}

Получение пленок на стеклянной подложке. Процесс синтеза частиц селенида цинка при взаимодействии ионов цинка с селеном в присут-

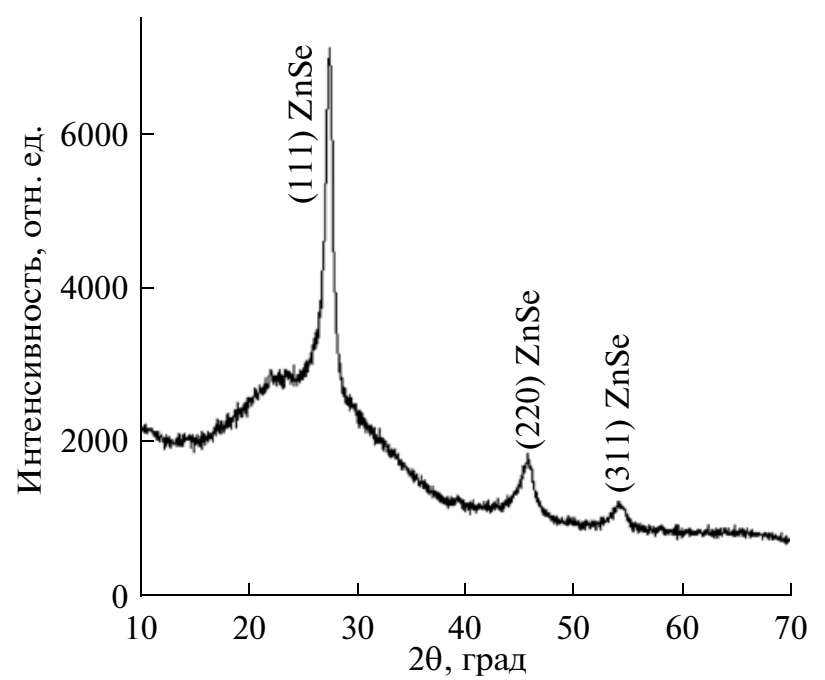

Рис. 1. Дифрактограмма пленки $\mathrm{ZnSe}$, полученной на стеклянной подложке из $3 \mathrm{M}$ раствора $\mathrm{NaOH}$ без добавки.

ствии гидразина можно описать следующими реакциями $[15,16]$ :

$$
\begin{gathered}
3 \mathrm{Se}+6 \mathrm{OH}^{-} \leftrightarrow 2 \mathrm{Se}^{2-}+\mathrm{SeO}_{3}^{2-}+3 \mathrm{H}_{2} \mathrm{O} \\
3 \mathrm{SeO}_{3}^{2-}+3 \mathrm{~N}_{2} \mathrm{H}_{4} \rightarrow 3 \mathrm{Se}^{2-}+3 \mathrm{~N}_{2}+3 \mathrm{H}_{2} \mathrm{O}+6 \mathrm{OH}^{-} \\
\mathrm{Zn}^{2+}+\mathrm{Se}^{2-} \rightarrow \mathrm{ZnSe}
\end{gathered}
$$

При добавлении сульфита натрия в реакционную смесь возможно образование селеносульфата натрия, являющегося селенирующим реагентом [17]:

$$
\begin{aligned}
\mathrm{Se}+\mathrm{Na}_{2} \mathrm{SO}_{3} & \rightarrow \mathrm{Na}_{2} \mathrm{SeSO}_{3}, \\
\mathrm{Zn}^{2+}+\mathrm{Na}_{2} \mathrm{SeSO}_{3}+\mathrm{H}_{2} \mathrm{O} & \rightarrow \mathrm{ZnSe}+\mathrm{Na}_{2} \mathrm{SO}_{4}+2 \mathrm{H}^{+}
\end{aligned}
$$

В процессе осаждения, вне зависимости от содержания добавки сульфита натрия в растворе, на стеклянных подложках формировались пленки светло-желтого оттенка. На рис. 1 представлена дифрактограмма пленки, полученной на стеклянной подложке при осаждении из $3 \mathrm{M}$ раствора $\mathrm{NaOH}$. На дифрактограмме присутствуют рефлексы, принадлежащие кубической модификации $\mathrm{ZnSe}$. Аналогичные результаты получены для пленок, синтезированных с добавлением в 3 М раствор $\mathrm{NaOH}$ сульфита натрия.

Микрофотографии поверхности полученных пленок представлены на рис. 2. Вне зависимости от условий синтеза пленки образованы сферическими частицами. Средний размер частиц, полученных из $3 \mathrm{M}$ раствора $\mathrm{NaOH}$ без добавки сульфита натрия, составляет 0.66 мкм (среднеквадратичное отклонение 0.08). Однако при этом пленка не является сплошной, и для получения более плотной пленки необходимо проведение повторного осаждения [12]. Введение сульфита натрия в раствор осаждения способствует формированию пленок с более высокой сплошностью. 

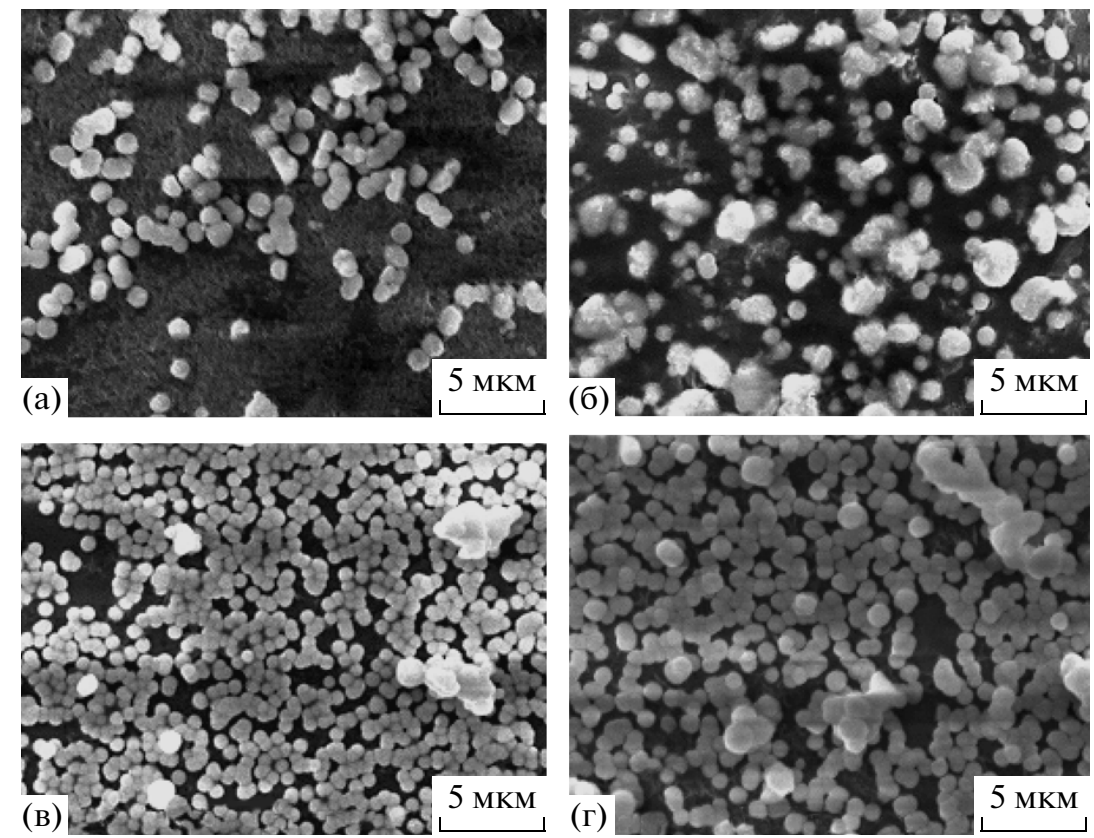

Рис. 2. Микрофотографии пленок $\mathrm{ZnSe}$, полученных из $3 \mathrm{M}$ раствора $\mathrm{NaOH}$ без добавления (а) и с добавлением сульфита натрия в соотношении $\mathrm{Zn}^{2+}: \mathrm{SO}_{3}^{2-}$, равном $1: 1$ (б), $1: 5$ (в), $1: 10$ (г).

$\mathrm{C}$ повышением соотношения $\mathrm{Zn}^{2+}: \mathrm{SO}_{3}^{2-}$ до $1: 5$ наблюдается уменьшение среднего размера частиц до 0.53 мкм (среднеквадратичное отклонение 0.06). Дальнейшее увеличение соотношения $\mathrm{Zn}^{2+}: \mathrm{SO}_{3}^{2-}$ до $1: 10$ приводит к укрупнению частиц: средний размер составляет 0.75 мкм (среднеквадратичное отклонение 0.08). На рис. 3 представлены результаты ИК-спектрометрического анализа пленки, полученной на стеклянной подложке при соотношении $\mathrm{Zn}^{2+}: \mathrm{SO}_{3}^{2-}=1: 1$ (спектр 1). Следует отметить, что ИК-спектры пленок, полученных в различных условиях, идентичны между собой. В

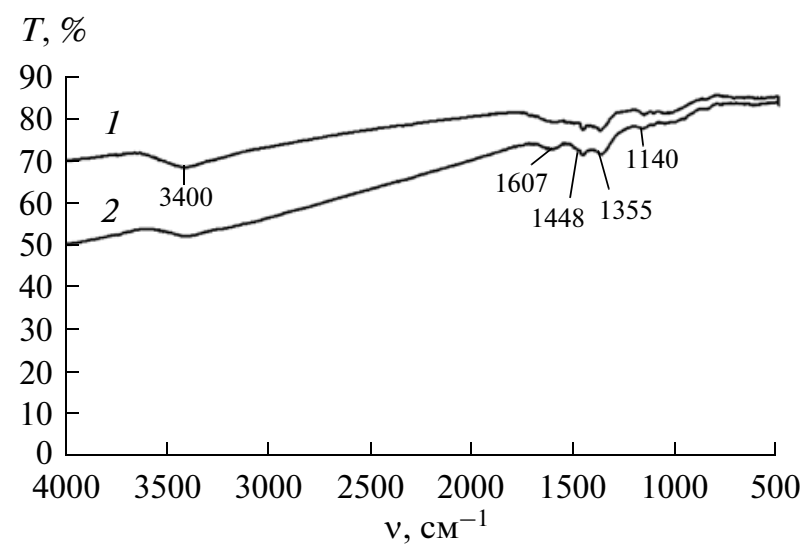

Рис. 3. ИК-спектры пленок, полученных из 3 М раствора $\mathrm{NaOH}$ на стеклянной подложке (1) и нержавеющей стали (2) при соотношении $\mathrm{Zn}^{2+}: \mathrm{SO}_{3}^{2-}$ до $1: 1$.
ИК-спектре 1 наблюдаются полосы поглощения в области 3000-3600 $\mathrm{cm}^{-1}$ с максимумами при 3400 и $1607 \mathrm{~cm}^{-1}$, связанные с валентными и деформационными колебаниями молекул воды соответственно $[13,14]$, что обусловлено использованием бромида калия. Также наблюдаются полосы поглощения при 1448 и $1355 \mathrm{~cm}^{-1}$, связанные с колебаниями иона $\mathrm{CO}_{3}^{2-}$, и полоса поглощения $1140 \mathrm{~cm}^{-1}$, связанная с колебаниями иона $\mathrm{SO}_{4}^{2-}$ [13].

На рис. 4 представлены спектры пропускания полученных пленок. Как видно, пленки характеризуются низким коэффициентом пропускания в видимой области спектра. Спад зависимостей для пленок с более высокой сплошностью (рис. 4, спектры 2, 4), связанный с межзонным переходом, происходит в области $\simeq 440$ нм.

Отражение света от пленок из-за развитого рельефа поверхности было на уровне предела чувствительности регистратора, поэтому в дальнейших расчетах использовалась постоянная величина, равная порогу чувствительности прибора. Для определения оптической ширины запрещенной зоны $E_{g}$ материала было использовано соотношение:

$$
\alpha h v=A\left(h v-E_{g}\right)^{1 / 2},
$$

где $A$ - константа, зависящая от эффективной массы носителей заряда в материале; $h v-$ энергия оптических квантов; $\alpha$ - коэффициент поглощения материала.

Из соотношения (6) следует, что экстраполяция линейной части графика $(\alpha h v)^{2}-h v$ на ось энергий 


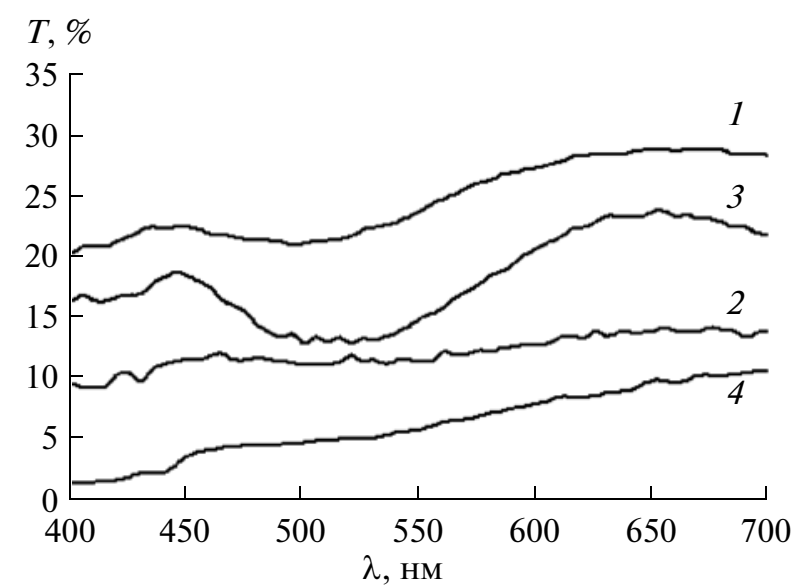

Рис. 4. Спектры пропускания пленок $\mathrm{ZnSe}$, полученных из $3 \mathrm{M}$ раствора $\mathrm{NaOH}$ без добавления (1) и с добавлением сульфита натрия в соотношении $\mathrm{Zn}^{2+}$ : : $\mathrm{SO}_{3}^{2-}$, равном $1: 1(2), 1: 5(3), 1: 10$ (4).

позволяет определить ширину запрещенной зоны материала. Спектральные зависимости коэффициентов поглощения пленок, необходимые для расчета $E_{g}$, были определены по спектрам пропускания с учетом постоянного, близкого к нулю, коэффициента отражения из соотношения:

$$
\alpha=-\frac{1}{d} \ln \left(\frac{1}{R^{2}}\left(-\frac{(1-R)^{2}}{2 T}+\sqrt{\frac{(1-R)^{4}}{4 T^{4}}+R^{2}}\right),\right.
$$

где $d-$ толщина пленки.
Поскольку зависимости $(\alpha h v)^{2}-h v$ для синтезированных пленок были подобны, в качестве примера на рис. 5 представлена одна из рассчитанных кривых, которые использованы для оценки ширины запрещенной зоны пленки ZnSe. Аппроксимация линейного участка такой зависимости на ось энергий позволяет определить $E_{g}$ присутствующих в пленке фаз.

Как следует из полученных результатов, ширина запрещенной зоны составляет 2.6-2.7 эВ, что соответствует табличным значениям для ZnSe. При этом варьирование концентрации добавки сульфита натрия не оказало влияния на величину ширины запрещенной зоны полученных пленок.

Формирование пленок на металлических подложках. С целью изучения электрических свойств проведено осаждение пленок на металлические подложки. На рис. 6, 7 представлены дифрактограммы пленок, полученных на металлических подложках при осаждении из $3 \mathrm{M}$ раствора $\mathrm{NaOH}$ с добавкой сульфита натрия в соотношении $\mathrm{Zn}^{2+}: \mathrm{SO}_{3}^{2-}=1: 5$. На дифрактограммах полученных пленок обнаружены рефлексы, принадлежащие кубической модификации $\mathrm{ZnSe}$ (сфалерит).

На рис. 8 представлены микрофотографии пленок, полученных на нержавеющей стали. Пленки сформированы сферическими частицами, размер которых зависит от условий осаждения. Пленка, полученная из $3 \mathrm{M} \mathrm{NaOH}$ на нержавеющей стали, состоит из частиц со средним размером 0.3 мкм. При введении добавки сульфита натрия средний

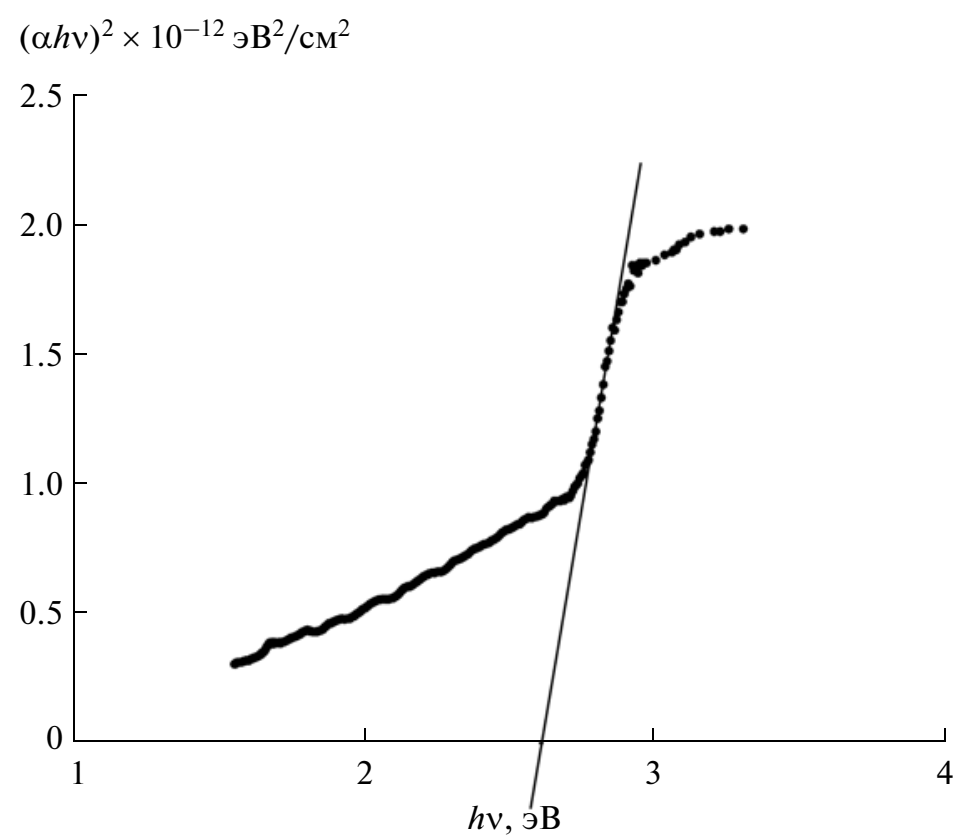

Рис. 5. Зависимость $(\alpha h v)^{2}-h v$ пленки $\mathrm{ZnSe}$, полученной из 3 М раствора $\mathrm{NaOH}$ с добавлением сульфита натрия в соотношении $\mathrm{Zn}^{2+}: \mathrm{SO}_{3}^{2-}=1: 5$. 


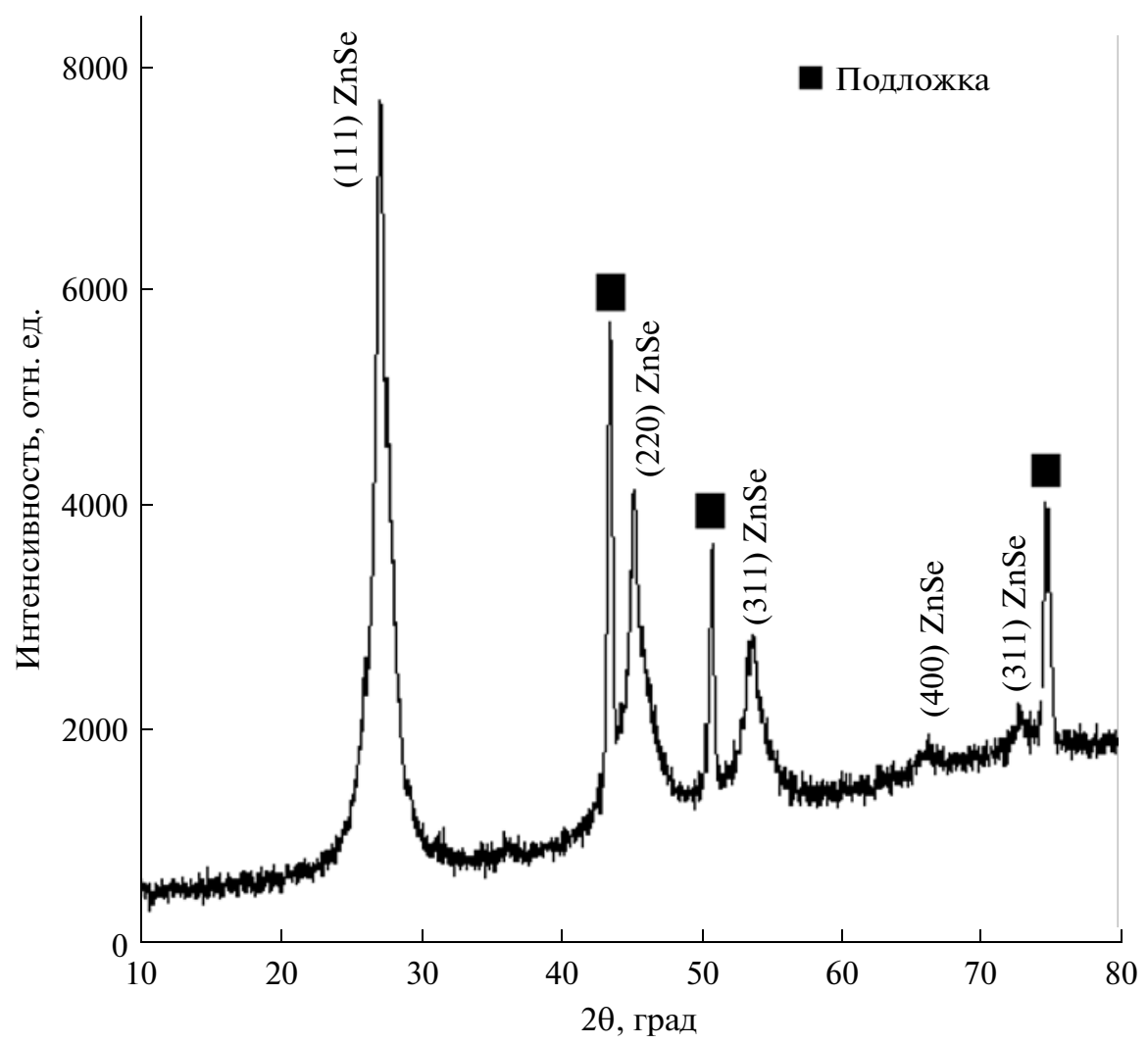

Рис. 6. Дифрактограмма пленки $\mathrm{ZnSe}$, полученной из $3 \mathrm{M}$ раствора $\mathrm{NaOH}$ с добавкой сульфита натрия в соотношении $\mathrm{Zn}^{2+}: \mathrm{SO}_{3}^{2-}=1: 5$ на подложке из нержавеющей стали.

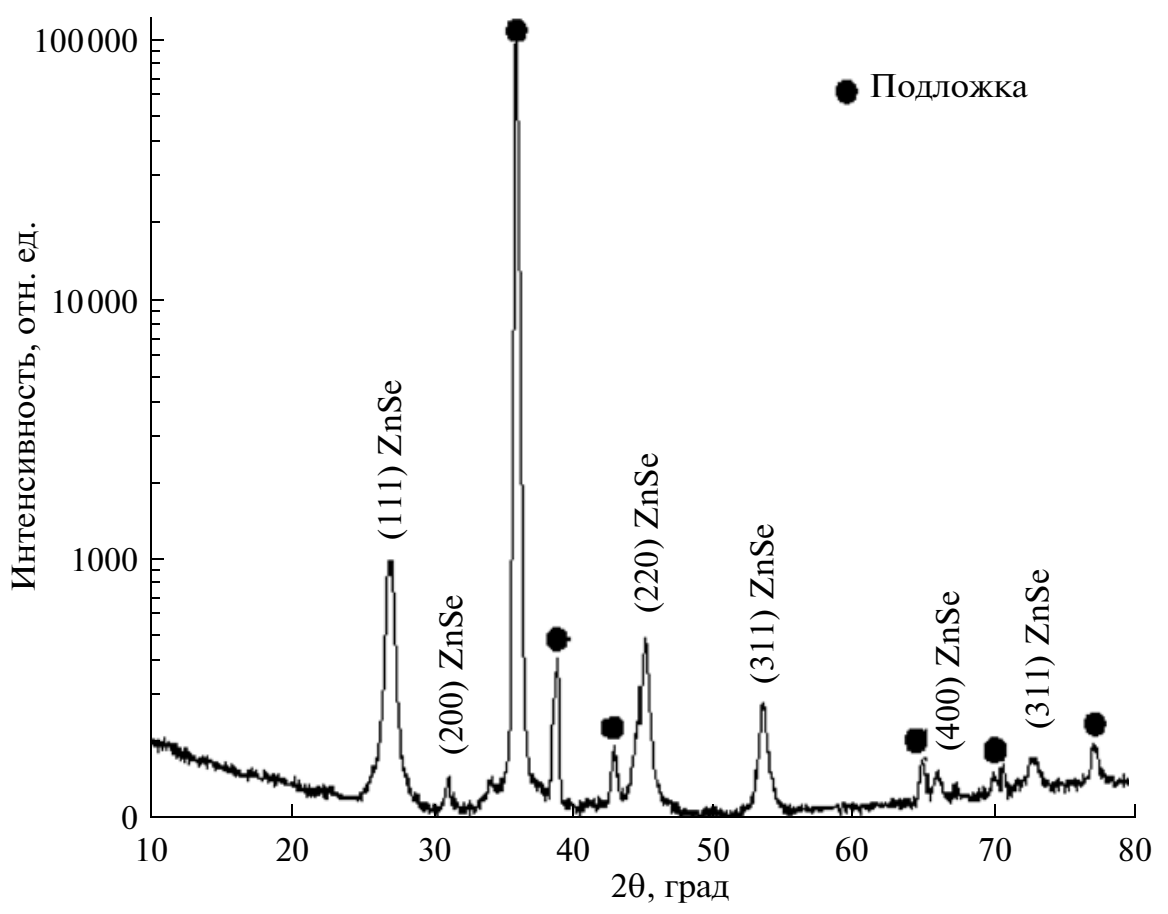

Рис. 7. Дифрактограмма пленки $\mathrm{ZnSe}$, полученной из $3 \mathrm{M}$ раствора $\mathrm{NaOH}$ с добавкой сульфита натрия в соотношении $\mathrm{Zn}^{2+}: \mathrm{SO}_{3}^{2-}=1: 5$ на подложке из оцинкованного железа. 

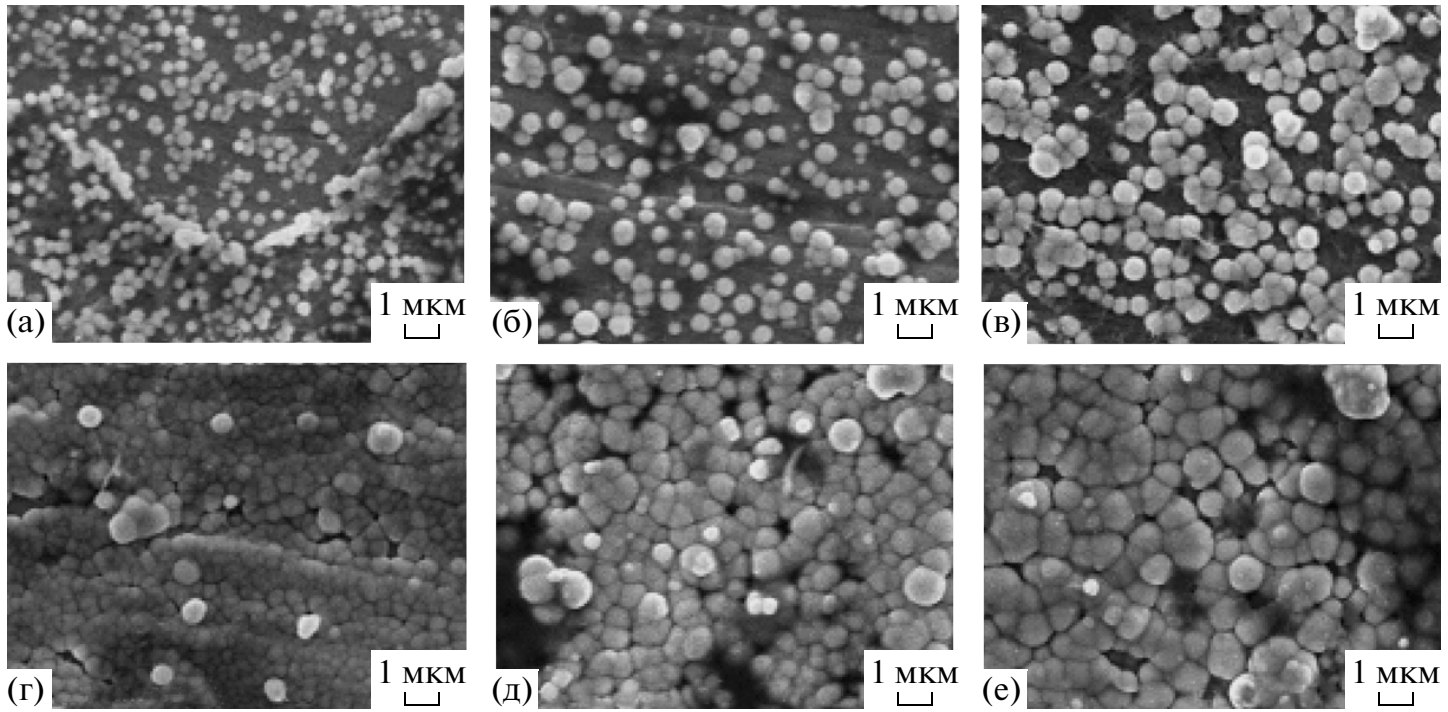

Рис. 8. Микрофотографии пленок $\mathrm{ZnSe}$, полученных из $3 \mathrm{M}$ раствора $\mathrm{NaOH}$ без добавки (а) и с добавкой сульфита натрия в соотношении $\mathrm{Zn}^{2+}: \mathrm{SO}_{3}^{2-}$, равном $1: 1$ (б, д), 1:5 (в) и 1:10 (г, е) на стали 12X18Н10Т при однократном (а-г) и двукратном (д, е) осаждении.

размер частиц увеличивается до 0.4 мкм. Увеличение концентрации добавки приводит к росту сплошности пленок (рис. 8а-8г). В случае двукратного осаждения пленки средний размер частиц составлял 0.7 мкм и практически не зависел от концентрации добавки сульфита натрия. В случае использования в качестве подложки оцинкованного железа наблюдается аналогичная ситуация. На поверхности подложки из оцинкованного железа пленки селенида цинка состоят из сферических частиц со средним размером 0.6 мкм. Введение добавки сульфита натрия способствует повышению сплошности пленок и укрупнению частиц.

ИК-спектры пленок, полученных на металлических подложках, были идентичны спектрам пленок, полученных на стеклянных подложках. В ИК-спектре 2 на рис. 3 присутствуют полосы поглощения при 1448 и $1355 \mathrm{~cm}^{-1}$, связанные с колебаниями

Электросопротивление пленок при различной концетрации сульфита натрия в растворе

\begin{tabular}{c|c|c}
\hline \multicolumn{1}{c|}{ Подложка } & $\mathrm{Zn}^{2+}: \mathrm{SO}_{3}^{2-}$ & $\rho \times 10^{-4}$, Ом см \\
\hline Нержавеющая сталь & $1: 1$ & 3.2 \\
\cline { 2 - 3 } & $1: 5$ & 6.6 \\
\cline { 2 - 3 } & $1: 10$ & 6.9 \\
\hline Оцинкованное железо & $1: 1$ & 2.7 \\
\cline { 2 - 3 } & $1: 5$ & 6.2 \\
\cline { 2 - 3 } & $1: 10$ & 7.4 \\
\hline
\end{tabular}

иона $\mathrm{CO}_{3}^{2-}$, и полоса поглощения $1140 \mathrm{~cm}^{-1}$, связанная с колебаниями иона $\mathrm{SO}_{4}^{2-}$.

В таблице приведены результаты измерения электрического сопротивления пленок при однократном нанесении на металлические подложки и различной концентрации сульфита натрия в растворе. Как следует из полученных экспериментальных данных, средняя величина удельного электрического сопротивления синтезированных пленок $\mathrm{ZnSe}$ на стали $12 \mathrm{X} 18 \mathrm{H} 10 \mathrm{~T}$ составляла порядка $1.5 \times 10^{4}$ Ом см без добавки $\mathrm{Na}_{2} \mathrm{SO}_{3}$. По мере роста концентрации $\mathrm{Na}_{2} \mathrm{SO}_{3}$ электросопротивление увеличивалось от $3.2 \times 10^{4}$ до $6.9 \times 10^{4}$ Ом см. Характер изменения электросопротивления пленок, полученных на поверхности оцинкованного железа, аналогичен. Пленки во всех случаях демонстрировали более низкое удельное электросопротивление по сравнению с массивными кристаллами $\mathrm{ZnSe}\left(7 \times 10^{7}\right.$ Ом см).

\section{ЗАКЛЮЧЕНИЕ}

Методом гидрохимического осаждения получены пленки селенида цинка из 3 М раствора $\mathrm{NaOH}$ и изучено влияние сульфита натрия в растворе осаждения на процесс формирования пленок. Установлено, что независимо от условий осаждения наблюдается формирование кубической модификации селенида цинка (сфалерит) с шириной запрещенной зоны $E_{g}=2.6-2.7$ эВ.

Введение в раствор осаждения сульфита натрия способствует формированию более сплошных пленок на подложках. С ростом концентра- 
ции сульфита натрия в растворе средний размер частиц увеличивается до 0.75 мкм (при соотношении $\left.\mathrm{Zn}^{2+}: \mathrm{SO}_{3}^{2-}=1: 10\right)$.

Пленки $\mathrm{ZnSe}$, полученные гидрохимическим методом, характеризуются величиной среднего удельного электросопротивления в пределах от $3 \times 10^{4}$ до $7 \times 10^{4}$ Ом см.

\section{СПИСОК ЛИТЕРАТУРЫ}

1. Michler P., Vehse M., Gutowski J., Behringer M., Hommel D., Pereira M.F., Henneberger K. Influence of Coulomb Correlate on Gain and Stimulated Emission in (Zn,Cd)Se/Zn(S,Se)/(Zn,Mg)(S,Se) Quantum-Well Lasers // Phys. Rev. B. 1998. V. 58. P. 2055-2063.

2. Pereira M.F., Henneberger K. Microscopic Theory for the Influence of Coulomb Correlations in the LightEmission Properties of Semiconductor Quantum Wells // Phys. Rev. B. 1998. V. 58. P. 2064-2069.

3. Jin L., Choy W.C.H., Leung Y.P., Yuk T.I., Ong H.C., Wang J.B. Synthesis and Analysis of Abnormal Wurtzite ZnSe Nanowheels // J. Appl. Phys. 2007. V. 102. № 4. P. 044302-044307.

4. Zhai T.Y., Zhong H.Z., Gu Z.J., Peng A.D., Fu H.B., Ma Y., Li Y.F., Uao J.N. Manipulation of the Morphology of ZnSe Sub-Micron Structures Using CdSe Nanocrystals as the Seeds // J. Phys. Chem. C. 2007. V. 111. № 7. P. 2980-2986.

5. Liu S.Y., Choy W.C.H., Jin L., Leung Y.P., Zheng G.P., Wang J.B., Soh A.K. Triple-Crystal Zinc Selenide Nanobelts // J. Phys. Chem. C. 2007. V. 111. № 26. P. 9055-9059.

6. Vij D.R. Luminescence of Solids. N.Y.: Plenum Press, 1998. $221 \mathrm{p}$.

7. Carles J., Mullins J.T., Brinkman A.W. Partial Pressure Monitoring in Cadmium Telluride Vapour Growth // J. Cryst. Growth. 1997. V. 174. № 1-4. P. 740-745.

8. Gaysinskiy V., Singh B., Ovechkina L., Miller S., Thacker S., Nagarkar V. Luminescence Properties and Morphology of ZnSe:Te Films // IEEE Trans. Nucl. Sci. 2008. V. 55. № 3. P. 1556-1560.
9. Марков В.Ф., Маскаева Л.Н. Расчет условий образования твердой фазы халькогенидов металлов при гидрохимическом осаждении. Екатеринбург: Издательство ГОУ-ВПО УГТУ-УПИ, 2005. 26 с.

10. Третьякова Н.А., Марков В.Ф., Маскаева Л.Н., Мухамедзянов Х.Н. Кинетика гидрохимического осаждения пленок селенида свинца, их состав, структура и свойства // Конденсированные среды и межфазные границы. 2005. Т. 7. № 2. С. 189-194.

11. Ягодин С.И., Миронов М.П., Маскаева Л.Н., Марков В.Ф. Кинетико-термодинамический анализ условий химического осаждения твердых растворов замещения в системе $\mathrm{PbSe}-\mathrm{CdSe} / /$ Конденсированные среды и межфазные границы. 2010. Т. 12. № 2. С. 177-183.

12. Софронов Д.С., Софронова Е.М., Костенюкова Е.И., Стариков В.В., Лебединский А.М., Матейченко П.В. Получение пленок $\mathrm{ZnSe}$ методом гидрохимического осаждения // J. Nano Electron. Phys. 2014. T. 6. № 1. C. 01016-4.

13. Sofronov D.S., Kamneva N.N., Bulgakova A.V., Mateychenko P.V., Baumer V.N., Belikov K.N., Chebanov V.A., Lavrynenko S.N., Mamalis A.G. Effect of Anions and Medium $\mathrm{pH}$ on the Formation of $\mathrm{ZnS}$ Micro- and Nanoparticles from Thiourea Solutions // J. Biol. Phys. Chem. 2013. V. 13. № 3. P. 85-89.

14. Sofronov D.S., Sofronova E.M., Baumer V.N., Kudin K.A., Mateichenko P.V., Vovk O.M., Bryleva E.Yu., Belikov K.N. Formation of $\mathrm{ZnS}$ Nano- and Microparticles from Thiourea Solutions // Adv. Powder Technol. 2013. V. 24. № 6. P. 1017-1022.

15. Cao F., Shi W., Zhao L., Song S., Yang J., Lei Y., Zhang H. Hydrothermal Synthesis and High Photocatalytic Activity of 3D Wurtzite ZnSe Hierarchical Nanostructures // J. Phys. Chem. C. 2008. V. 112. № 44. P. 17095-17101.

16. Du J., Xu L., Zou G., Chai L., Qian Y. A Solvothermal Method to Novel Metastable ZnSe Nanoflakes // Mater. Chem. Phys. 2007. V. 103. № 3. P. 441-445.

17. Китаев Г.А., Хворенкова А.Ж. Анализ условий получения селенидов металлов в водных растворах селеносульфата натрия // Журн. прикл. химии. 1998. T. 71. № 8. C. 1261-1264. 